\title{
Prevalence and Pattern Occurrence of Supernumerary Teeth in the North-East Heilongjiang Population of China
}

\author{
Nyimi Bushabu Fidele ${ }^{1 *}$, Sekele Isouradi Bourley², Em Kalala Kazadi ${ }^{3}$, \\ Mantshumba Milolo Augustin ${ }^{2}$, Rubina Suwal ${ }^{1}$, Muyembi Muinamiyi ${ }^{4}$, \\ Duan Feng1, Guan Jian' \\ ${ }^{1}$ Unit I, Department of Oral and Maxillofacial Surgery, Second Affiliated Hospital of Jiamusi University, \\ Jiamusi, China \\ ${ }^{2}$ Prosthodontics and Orthodontics Service, Affiliated Hospital of Kinshasa University, Kinshasa, DR. Congo \\ ${ }^{3}$ Unit of Periodontics, Stomatology and Maxillofacial Service, Affiliated Hospital of Kinshasa University, \\ Kinshasa, DR. Congo \\ ${ }^{4}$ Unit of Oral Surgery, Stomatology and Maxillofacial Service, Affiliated Hospital of Kinshasa University, \\ Kinshasa, DR. Congo \\ Email: fidelenyimi@yahoo.fr
}

Received 29 December 2015; accepted 20 February 2016; published 23 February 2016

Copyright (C) 2016 by authors and Scientific Research Publishing Inc.

This work is licensed under the Creative Commons Attribution International License (CC BY). http://creativecommons.org/licenses/by/4.0/

(c) () Open Access

\section{Abstract}

Aims: The objective of the current research was to determine the prevalence of supernumerary teeth and investigate its characteristic and complications in the Chinese population from the NorthEast Heilongjiang region. Materials and Methods: It was a descriptive and retrospective study which used registered notes and panoramic radiographs of 12,984 patients who visited the Department of Oral and Maxillofacial Surgery in the $2^{\text {nd }}$ Affiliated Hospital of Jiamusi University, China between June 2011 to November 2015. Patients diagnosed with any syndrome or hereditary diseases were excluded from the study. The features of supernumerary teeth were noted and the data were analyzed using SPSS program, (version 20, Inc., Chicago, USA). The Chi-square test was used to determine the differences in the distribution of supernumerary teeth. It was tested at the $5 \%$ level of significance. Results: The prevalence was $5.2 \%$ and the most prevalent supernumerary teeth was incisor with $3.39 \%(n=441)$. The supernumerary teeth were seen more in maxilla than mandible. The male to female ratio was 2.9:1. Specifically, higher prevalence of supernumerary teeth in male gender was statistically significant $(p=0.03)$. The supernumerary teeth mostly occurred in children of 5 - 10 years (62.3\%), followed by young adolescent between 11 - 16 years $(\mathbf{2 6 . 5 \% )}$ ). Conclusion: The prevalence of supernumerary teeth was widely seen in children

${ }^{*}$ Corresponding author.

How to cite this paper: Fidele, N.B., Bourley, S.I., Kazadi, E.K., Augustin, M.M., Suwal, R., Muinamiyi, M., Feng, D. and Jian, G. (2016) Prevalence and Pattern Occurrence of Supernumerary Teeth in the North-East Heilongjiang Population of China. Open Journal of Stomatology, 6, 47-53. http://dx.doi.org/10.4236/ojst.2016.62006 
and young adolescent of Chinese population. The occurrence was mostly seen in maxilla than mandible and significantly higher in male than female.

\title{
Keywords
}

\author{
Prevalence, Occurrence, Supernumerary Teeth, Features
}

\section{Background}

Supernumerary teeth are a dental anomaly of number characterized by the presence of an additional tooth in the normal series. This condition is also called hyperdontia. The aetiology is unknown, yet various theories have been suggested for the presence of supernumerary tooth, such as dichotomy of the tooth bud, hyperactivity of the dental lamina and genetic effect and environmental factors combined [1] [2]. These teeth have been found in both primary and permanent dentition. However, the appearance of supernumerary teeth is higher in the permanent dentition than the primary dentition [3].

According to various studies, supernumerary teeth are more frequently seen among males than females with a proportion of 1:8 to 2:6 [4]-[7]. It may be found in any region of the dental arch, but the most common site in the midline between the 2 maxillary central incisors, where it is referred as mesiodens. This is commonly followed by maxillary lateral incisor, maxillary fourth molar, mandibular third premolar, maxillary premolar, and maxillary canine and mandibular fourth molar in a descending order. They might occur on one or both jaws and vary from single or double to multiple in number. It can be unilateral or bilateral [8]. Supernumerary teeth are also widely seen in association with syndromes, such as cleft lip and palate, Cleidocranial dysplasia, Down's syndromes, Gardner's syndrome, Gorlin-Sedano syndrome, etc. [9] [10]. They account for $80 \%$ of all supernumerary teeth [3].

The presence of supernumerary teeth results in different well-known complications such as uneruption or delayed eruption, ectopic eruption, displacement, diastemas, occlusal problems, rotated neighboring teeth, radicular resorption and cyst formation [8] [11]. But in some cases, supernumerary teeth are asymptomatic and they cannot be diagnosed without routine radiographic examination, if they do not appear in the oral and maxillofacial region.

Many studies showed that, the prevalence of supernumerary teeth was diversely reported and varies according to race, ethnicity and geographic situation. The prevalence reported in the literature of hyperdontia varied between $0.2 \%-0.8 \%$ in the primary dentition, and between $0.5 \%$ to $5.6 \%$ in the permanent dentition of the general population [11]-[16]. No study has been done for to assess the prevalence and occurrence of supernumerary teeth in the North-East Chinese population from Heilongjiang Region.

The objective of the present research was to determine the prevalence of supernumerary teeth and investigate its characteristic and complications in the Chinese population from the North Heilongjiang region.

\section{Materials and Methods}

A survey was performed on 12,984 patients (9584 males and 3400 females) with age ranging from 5 to 76 years and without any story previous surgical extraction attending the Department of Oral and Maxillofacial Surgery, $2^{\text {nd }}$ Affiliated Hospital of Jiamusi University, Heilongjiang Province, China over a period of four years was examined for the present retrospective and descriptive study. Out of 12,984 in total patients, 681 of them (510 were male and 171 were female) who had supernumerary teeth were randomly selected and included in our study. The reasons for their visit to our Hospital was dental caries, malocclusion, delay or lack of the eruption of permanent teeth, trauma of maxillofacial region and a routine dental check-up. Patients diagnosed with any syndrome or hereditary diseases and those who had any injury were excluded from the research work. Deciduous supernumerary teeth were included that justify the non-evaluation of the permanent supernumerary teeth classification.

The patient's dental records and radiographs were examined in order to detect all types of supernumerary teeth. All panoramic radiographs were taken with the Dentsply Gendex Orthoralix 9200 (Dentsply Asia, Milford, US), and the magnification factor was 1.23. The first group of researchers examined the radiographs at the same 
time on standard light boxes to determine the supernumerary tooth. And the second groups researches were inspected the patient's register and the consult form.

All supernumerary teeth were noted and diagnosed with a detailed clinical and panoramic radiographic examination. For each patient we recorded the demographic variables including age and gender and all information collected was recorded in a special form. According to the diagnosis, all supernumerary teeth were classified under several categories such as: location (maxilla or mandible, specifying the region from anterior to posterior), orientation (vertical, angled, horizontal, and inverted). The data was entered into computer and analyzed using SPSS program, (version 20. Inc., Chicago, USA). The differences between the groups were tested using the Chisquare test. It was tested at the $5 \%$ level of significance.

\section{Results}

All of 12,984 patients were examined, among which 9584 were males (73.8\%) and 3400 were females (26.2\%), with an age range of 5 - 76 years and a mean age of 18 (SD \pm 4 ) years. Out of the 12,984 patients, a total of 681 patients (510 males and 171 females) were included in our study (Table 1).

The prevalence of supernumerary teeth was $5.2 \%$ and the incisor was the most prevalent supernumerary teeth with $3.39 \%(n=441)$, followed by premolars $(0.75 \% ; n=98)$, canines $(0.46 \% ; n=61)$ and by molars $(0.42 \%$; $\mathrm{n}=54)$. The deciduous teeth was noted by $(0.20 \% ; n=27)$ (Table 2$)$. The prevalence of supernumerary teeth was most in maxilla than mandible.

In Table 3, the frequency of supernumerary teeth was more in maxillary $(90.5 \% ; n=708)$ than mandible $(9.5 \% ; n=74)$ and more in male $(74.6 \% ; n=583)$ than female $(25.4 \% ; n=199)$ with a ratio of $2.9: 1$. The precisely higher prevalence of supernumerary teeth in male gender was statistically significant $(P=0.03)$. And $A$ significant difference was found between localisation of supernumerary teeth in maxilla and mandible $(\mathrm{P}=0.01)$.

The Supernumerary teeth mostly occurred in children between 5 - 10 years $(62.3 \%$; $n=487)$, followed by young adolescent population between 11 - 16 years $(26.5 \%$; $n=207)$ (Table 4).

Table 5 shows the characteristics of supernumerary teeth. In $75.7 \%(n=592)$ of patients, one supernumerary tooth was observed and in $21.9 \%(\mathrm{n}=86)$ of patients two supernumerary teeth were observed. Three patients $(2.3 \% ; n=18)$ had three or more than three supernumerary teeth. In terms of orientation, $65.7 \%(n=514)$ of all supernumerary teeth were vertical. Regarding to the state of eruption within the arch, 280 supernumerary teeth (35.8\%) had erupted and 478 supernumerary teeth (61.1\%) did not cause any complications. However, 243 teeth (31.1\%) caused impaction and 61 teeth (7.8\%) caused displacement of the adjacent teeth.

Table 1. Distribution of patients and supernumerary teeth depending to gender.

\begin{tabular}{cccc}
\hline Gender & Number & $\begin{array}{c}\text { Number of patients } \\
\text { Had supernumery teeth }\end{array}$ & Number of teeth \\
\hline Male & $9584(73.8 \%)$ & 510 & $583(74.6 \%)$ \\
Female & $3400(26.2 \%)$ & 171 & $199(25.4 \%)$ \\
Total & 12,984 & $\mathbf{6 8 1} \mathbf{( 1 0 0 \% )}$ & $\mathbf{7 8 2}(\mathbf{1 0 0 \% )}$ \\
\hline
\end{tabular}

$P$ value $=0.03$

Table 2. Distribution of patients according to the type of impacted teeth and prevalence of supernumerary teeth.

\begin{tabular}{|c|c|c|c|c|}
\hline Supernumerary teeth & Male & Female & No. of patients & Prevalence \\
\hline Incisor & 371 & 70 & 441 & 3.39 \\
\hline Canines & 39 & 22 & 61 & 0.46 \\
\hline Premolars & 51 & 47 & 98 & 0.75 \\
\hline Molars & 30 & 24 & 54 & 0.42 \\
\hline Deciduous teeth & 19 & 8 & 27 & 0.20 \\
\hline Total & 510 & 171 & 681 & 5.2 \\
\hline
\end{tabular}

Legend: No., number. 
Table 3. Distribution of supernumerary teeth according to gender and localisation.

\begin{tabular}{|c|c|c|c|c|c|}
\hline Supernumerary teeth & Male & Female & Total & Maxilla & Mandible \\
\hline \multirow{2}{*}{$\begin{array}{l}\text { Central incisor } \\
\text { Lateral incisor }\end{array}$} & $330(42.2 \%)$ & $68(8.7 \%)$ & $398(50.9 \%)$ & $374(47.8 \%)$ & $24(3 \%)$ \\
\hline & 82 (10.5\%) & $18(2.3 \%)$ & $100(12.8 \%)$ & 91 (11.6\%) & $9(1.2 \%)$ \\
\hline Canines & 49 (6.3\%) & $25(3.2 \%)$ & $74(9.5 \%)$ & 67 (8.6\%) & 7 (0.9\%) \\
\hline Premolars & $58(7.4 \%)$ & $55(7 \%)$ & $113(14.5 \%)$ & 99 (12.7\%) & $14(1.8 \%)$ \\
\hline Molars & $37(4.7 \%)$ & $24(3 \%)$ & $61(7.8 \%)$ & $44(5.6 \%)$ & $17(2.2 \%)$ \\
\hline Deciduous teeth & 27 (3.5\%) & $9(1.2 \%)$ & $36(2.59 \%)$ & $33(4.2 \%)$ & $3(0.4 \%)$ \\
\hline Total & $583(74.6 \%)$ & $199(25.4 \%)$ & $782(100 \%)$ & $708(90.5 \%)$ & $74(9.5 \%)$ \\
\hline
\end{tabular}

Table 4. Distribution of Supernumerary teeth according to age group.

\begin{tabular}{cc}
\hline Agegroup & Supernumerary \\
\hline $5-10$ & $487(62.3 \%)$ \\
$11-16$ & $207(26.5 \%)$ \\
$17-22$ & $30(3.8 \%)$ \\
$23-28$ & $38(4.9 \%)$ \\
$29-34$ & $6(0.6 \%)$ \\
$35-39$ & $0(0 \%)$ \\
$40-45$ & $0(0 \%)$ \\
$46-51$ & $11(1.4 \%)$ \\
$52-57$ & $0(0 \%)$ \\
$\geq 58$ & $3(0.4 \%)$ \\
Total & $\mathbf{7 8 2}(\mathbf{1 0 0} \%)$ \\
\hline
\end{tabular}

Table 5. Feature of supernumerary teeth.

\begin{tabular}{|c|c|c|c|c|}
\hline \multicolumn{3}{|c|}{ Supernumerary teeth feature } & \multirow{2}{*}{$\begin{array}{c}\text { Number of teeth } \\
782\end{array}$} & \multirow{2}{*}{$\begin{array}{c}\text { Percentage } \\
100\end{array}$} \\
\hline Total number & & & & \\
\hline \multirow{4}{*}{ Orientation } & \multicolumn{2}{|c|}{ Vertical } & 514 & 65.7 \\
\hline & \multicolumn{2}{|c|}{ Angled (Mesio or Disto-angular) } & 143 & 18.3 \\
\hline & \multicolumn{2}{|c|}{ Transverse } & 67 & 8.6 \\
\hline & \multicolumn{2}{|c|}{ Inverted } & 58 & 7.4 \\
\hline \multirow{4}{*}{ Number } & Teeth number & Patient number & & \\
\hline & 1 & 592 & 592 & 75.7 \\
\hline & 2 & 86 & 172 & 21.9 \\
\hline & $\geq 3$ & 3 & 18 & 2.3 \\
\hline \multirow{2}{*}{ Status } & \multirow{2}{*}{\multicolumn{2}{|c|}{$\begin{array}{c}\text { Impacted } \\
\text { Erupted }\end{array}$}} & 502 & 64.2 \\
\hline & & & 280 & 35.8 \\
\hline \multirow{3}{*}{ Complications } & \multicolumn{2}{|c|}{ Asymptomatic } & 478 & 61.1 \\
\hline & \multicolumn{2}{|c|}{ Impaction } & 243 & 31.1 \\
\hline & \multicolumn{2}{|c|}{ Crowding } & 61 & 7.8 \\
\hline
\end{tabular}

\section{Discussion}

Supernumerary teeth or hyperdontia is described as abnormal alterations of the teeth formed excess in number either in the primary or permanent dentition. They are mostly seen in association with syndromes and the aetiology is unknown, but various theories have been suggested [1] [2] [9] [10]. The clinical complications are not 
uncommon in patients with supernumerary teeth; whereas teeth displacement and failure of eruption are the most frequently seen complications [17].

Although this study may not represent the North-East Heilongjiang population as a whole, the results are useful for primary health workers because the patients studied represent the range of dental patients presenting to Second Affiliated Hospital (Dental Hospital) of Jiamusi University. Many studies showed that, the prevalence of supernumerary teeth are differently reported and varies among different racial and ethnic groups. The prevalence was between $1 \%$ - 3\% in Caucasian population, greater than 3\% in Asians and between $0.42 \%$ to $5.6 \%$ in Africa [18] [19].

In our study, the prevalence in the North-East Heilongjiang Chinese population was $5.2 \%$ in which the central incisor presented $3.39 \%$. This higher rate of prevalence can be explained by the fact that the variations due to differences in demographic and environmental factors and different sample size susceptibilities that may have impact on the reported prevalence rate. Those studies which found this variation of prevalence are not close with our study. This difference can also be explained by the fact that the included population in those studies was only the children and young population but the recent study included all patients of the different age from 5 to 76 years old and hence may be justify this increased prevalence rate.

In the literature till date, the incidence of supernumerary teeth is usually higher in males than in females and the reported male to female ratio was between 1.18:1 to 4.5:1 which is similar to the present study that showed male to female ratio was 2.9:1. It is also reported correspondingly by other study in Caucasians and study by Patil S and Maheshwari S [4] [5].

Hence, our research also shows that the proportion of supernumerary teeth in relation to sex was also more prevalent in male population ( $\mathrm{P}<0.001$ ). The ratio between males and females was found diverged than our study in some literature, such as study of Liu et al. in china with 2.64:1 (male/female), study of Esenlik et al. in turkey (1.13:1), study of Rajab \& Hamdan (2.2:1) and in study made by Çelikoğlu who had noted 1.8:1 ration male to female [6] [7] [19] [20]. In addition, the male to female ratio was 6.5:1 in the different study of Chinese children [22]. The results of these research showing variables frequencies in sex ratio may be due to racial differences or possible sampling differences which also showed the variation of sex ratios in China. This situation can also be explained by the fact by there is differences between the age range, the number of examined patients, the limited number of the effected subjects and the methods used in these studies.

In the data from the literature the age of patients with supernumerary teeth ranges from 5 to 76 years; but most observed between the age group of 7 and 10 [7] [23]. Esenlik et al. reported in his research most cases were found between the age of seven and nine [20]. This affirmation are similar to our result, which most supernumerary teeth were found in age group between $5-10$ years $(62.3 \%$; $n=487)$, followed by age group between 11 - 16 years $(26.5 \%$; $n=207)$. Even though the prevalence of supernumerary teeth was seen highest among age group of 5 - 10 years and 11 to 16 years, it was seen decreasing with increasing age and independent of gender.

Many studies has identified that the most commonly involved location of supernumerary teeth is the premaxilla [20] [23]. In our present study, the premaxillary regions was the predominant location of supernumerary teeth and 50.9\% of this teeth were mesiodens which is similar to study reported by Montenegro et al. and Bäckman and Wahlin [24] [25]. This situation may be explained by obvious complications of mesiodens which makes it easily diagnosed by the parents and this affects the number of referrals.

Regarding the location of observed supernumerary teeth in this research, $90.5 \%(\mathrm{n}=708)$ of the supernumerary teeth were found in the maxillary arch. These results were similar to these of the data reported by De Oliveira Gomes et al. who found that $91.3 \%$ of the supernumerary teeth were found in the maxillary arch [21]. Our results are also superposable to these studies of Hattab et al., and Zhu et al. who showed that $90 \%$ of supernumerary teeth were found in the maxillary bone and this supports our conclusions [26] [27]. The incisor $(63.7 \% ; n=498)$ were the most commonly appearing supernumerary teeth which central incisor $(50.9 \%$; $n=$ 398) being the most common among them, like wise reported by Hyun et al. and Dermiriz et al. [28] [29]. The recent study noted an occurrence of supernumerary teeth in the deciduous dentition by a prevalence of $0.20 \%$ and all in maxilla analogous to others authors who had showed that, the prevalence of supernumerary teeth ranges from $0.2 \%$ to $0.8 \%$ in the deciduous dentition [7] [16].

From the literature data, supernumerary teeth may occur in either single or multiples number in any region of the jaws of the same person. It is well-known that, supernumerary teeth are more frequently single tooth, while multiple supernumerary teeth are normally two in number [7] [19] [21]. However, multiple supernumerary teeth 
co-exist rarely without any diseases or syndromes. According to our results, 75.7\% $(n=592)$ of the supernumerary teeth were found to be single and $21.9 \%(n=172)$ were found double and multiples supernumerary teeth were found in $2.3 \%$. Our conclusions coincide with the ones given in the literature data.

About the eruption status, we found out that $35.8 \%(n=280)$ of the supernumerary teeth were erupted. Our results were close to other studies reported about erupted supernumerary teeth [7] [20] [23] [29]. All erupted supernumerary teeth were normally-orientated while none of the transverse or inverted supernumerary teeth were erupted. So, we verified that erupted supernumerary teeth were commonly vertical with $65.7 \%(n=514)$. The detection of supernumerary teeth is very necessary but early diagnosis helps to prevent or minimize possible complications is even more important [7] [30]. Clinical complications were seen in 38.9\% of the supernumerary teeth. Displacement and impaction were the most frequent complication which is also reported by many authors [7] [20] [23].

\section{The Limitations of This Study}

We hope a larger size of sample which also includes from different city and hospitals of the North-East Heilongjiang province than used in this study.

\section{Conclusions}

The prevalence of supernumerary teeth in the North-East Heilongjiang region was higher and its frequency was mostly in children between 5 to 10 years followed young adolescent population between 11 to 16 years old.

The early diagnosis and the appropriate treatment should be considered to prevent the several complications of supernumerary teeth particularly the displacement of the surrounding teeth and failure to erupt the permanent teeth. However, an etiologic factor remains unidentified and therefore we expect a further study regarding its cause to determine the possible preventive measures that influence the prevalence.

\section{Acknowledgements}

The authors would like to thank Pr. Dr. Meng Cun Fang, Heard of Department of Radiology and nuclear medicine in the Second Affilited Hospital of Jiamusi University for it help to interpretation of radiographs.

\section{Competing Interests}

Authors have declared that there is no competing interest.

\section{References}

[1] Liu, J.F. (1995) Characteristics of Premaxillary Supernumerary Teeth: A Survey of 112 Cases. ASDC Journal of Dentistry for Children, 62, 262-265.

[2] Garvey, M.T., Barry, H.J. and Blake, M. (1999) Supernumerary Teeth-An Overview of Classification, Diagnosis and Management. Journal of the Canadian Dental Association, 65, 612-616.

[3] Russel, K.A. and Folwarczna, M.A. (2003) Mesiodens-Diagnosis and Management of a Common Supernumerary Tooth. Journal of the Canadian Dental Association, 69, 362-366.

[4] Ferrés-Padró, E., Prats-Armengol, J. and Ferrés-Amat, E. (2009) A Descriptive Study of 113 Unerupted Supernumerary Teeth in 79 Pediatric Patients in Barcelona. Medicina Oral, Patología Oral y Cirugía Bucal, 14, e146-e152.

[5] Patil. S. and Maheshwari, S. (2014) Prevalence of Impacted and Supernumerary Teeth in the North Indian Population. Journal of Clinical and Experimental Dentistry, 6, e116-e120. http://www.medicinaoral.com/odo/volumenes/v6i2/jcedv6i2p116.pdf http://dx.doi.org/10.4317/jced.51284

[6] Liu, D.G., Zhang, W.L., Zhang, Z.Y., Wu, Y.T. and Ma, X.C. (2007) Three-Dimensional Evaluations of Supernumerary Teeth Using Cone-Beam Computed Tomography for 487 Cases. Oral Surgery, Oral Medicine, Oral Pathology, Oral Radiology, and Endodontology, 103, 403-411. http://dx.doi.org/10.1016/j.tripleo.2006.03.026

[7] Rajab, L.D. and Hamdan, M.A. (2002) Supernumerary Teeth: Review of the Literature and a Survey of 152 Cases. International Journal of Paediatric Dentistry, 12, 244-254. http://dx.doi.org/10.1046/j.1365-263X.2002.00366.x

[8] Kara, M.I., Aktan, A.M., Ay, S., Bereket, C., Şener, İ., Bülbül, M., Ezirganlı, Ş. and Polat, H.B. (2012) Characteristics of 351 Supernumerary Molar Teeth in Turkish Population. Medicina Oral, Patología Oral y Cirugía Bucal, 17, e395e400. http://dx.doi.org/10.4317/medoral.17605 
[9] Bayar, G.R., Ortakolu, K. and Sencimen, M. (2008) Multiple Impacted Teeth: Report of Three Cases. European Journal of Dentistry, 2, 73-78.

[10] Sujatha, G., Sivapathasundharam, B., Sivakumar, G., Nalikumar, S., Ramasamy, M. and Prasad, T.S. (2012) Idiopathic Multiple Impacted Teeth: Case Report and Discussion. Journal of Oral and Maxillofacial Pathology, 16, 125-127. http://dx.doi.org/10.4103/0973-029X.92989

[11] Mali, S., Karjodkar, F.R., Sontakke, S. and Sansare, K. (2012) Supernumerary Teeth in Non-Syndromic Patients. Imaging Science in Dentistry, 42, 41-45. http://dx.doi.org/10.5624/isd.2012.42.1.41

[12] Ferres-Padro, E., Prats-Armengol, J. and Ferres-Amat, E. (2009) A Descriptive Study of 113 Unerupted Supernumerary Teeth in 79 Pediatric Patients in Barcelona. Medicina Oral Patologia Oral y Cirugia Bucal, 14, E146-E152.

[13] Tuna, E.B., Kurklu, E., Gencay, K. and Ak, G. (2013) Clinical and Radiological Evaluation of Inverse Impaction of Supernumerary Teeth. Medicina Oral Patologia Oral y Cirugia Bucal, 18, 613-618. http://dx.doi.org/10.4317/medoral.18877

[14] Sharma, A. and Singh, V.P. (2012) Supernumerary Teeth in Indian Children: A Survey of 300 Cases. International Journal of Dentistry, 2012, Article ID: 745265. http://dx.doi.org/10.1155/2012/745265

[15] Fardi, A., Kondylidou-Sidira, A., Bachour, Z., Parisis, N. and Tsirlis, A. (2011) Incidence of Impacted and Supernumerary Teeth—A Radiographic Study in a North Greek Population. Medicina Oral Patologia Oral y Cirugia Bucal, 16, e56-e61. http://dx.doi.org/10.4317/medoral.16.e56

[16] Gábris, K., Fábián, G., Kaán, M., Rózsa, N. and Tarján, I. (2006) Prevalence of Hypodontia and Hyperdontia in Paedodontic and Orthodontic Patients in Budapest. Community Dental Health, 23, 80-82.

[17] Solares, R. (1990) The Complications of Late Diagnosis of Anterior Supernumerary Teeth: Case Report. Journal of Dentistry for Children, 57, 209-211.

[18] Tay, F., Pang, A. and Yuen, S. (1984) Unerupted Maxillary Anterior Supernumerary Teeth: Report of 204 Cases. Journal of Dentistry for Children, 51, 289-294.

[19] Çelikoğlu, M., Kamak, H. and Oktay, H. (2010) Prevalence and Characteristics of Supernumerary Teeth in a NonSyndrome Turkish Population: Associated Pathologies and Proposed Treatment. Medicina Oral Patologia Oral y Cirugia Bucal, 15, 575-578. http://dx.doi.org/10.4317/medoral.15.e575

[20] Esenlik, E., Sayın, M.Ö., Atilla, A.O., Özen, T., Altun, C. and Başak, F. (2009) Supernumerary Teeth in a Turkish Population. American Journal of Orthodontics and Dentofacial Orthopedics, 136, 848-852. http://dx.doi.org/10.1016/j.ajodo.2007.10.055

[21] De Oliveira Gomes, C., Drummond, S.N., Jham, B.C., Abdo, E.N. and Mesquita, R.A. (2008) A Survey of 460 Supernumerary Teeth in Brazilian Children and Adolescents. International Journal of Paediatric Dentistry, 18, 98-106. http://dx.doi.org/10.1111/j.1365-263X.2007.00862.x

[22] Davis, P.J. (1987) Hypodontia and Hyperdontia of Permanent Teeth in Hong Kong School Children. Community Dentistry and Oral Epidemiology, 15, 218-220. http://dx.doi.org/10.1111/j.1600-0528.1987.tb00524.x

[23] Mukhopadhyay, S. (2011) Mesiodens: A Clinical and Radiographic Study in Children. Journal of Indian Society of Pedodontics and Preventive Dentistry, 29, 34-38. http://dx.doi.org/10.4103/0970-4388.79928

[24] Fernández Montenegro, P., Valmaseda Castellón, E., Berini Aytés, L. and Gay Escoda, C. (2006) Retrospective Study of 145 Supernumerary Teeth. Medicina Oral Patologia Oral y Cirugia Bucal, 11, 339-344.

[25] Bäckman, B. and Wahlin, Y.B. (2001) Variations in Number and Morphology of Permanent Teeth in 7-Year-Old Swedish Children. International Journal of Paediatric Dentistry, 11, 11-17. http://dx.doi.org/10.1046/j.1365-263x.2001.00205.x

[26] Hattab, E.N., Yassin, O.M. and Rawashdeh, M.A. (1994) Supernumerary Teeth: Report of Three Cases and Review of the Literature. ASDC Journal of Dentistry for Children, 61, 382-393.

[27] Zhu, J., Marcushamer, M., King, D.L. and Henry, R.J. (1996) Supernumerary and Congenitally Absent Teeth: A Literature Review. The Journal of Clinical Pediatric Dentistry, 20, 87-95.

[28] Hyun, H.K., Lee, S.J., Lee, S.H., Hahn, S.H. and Kim, J.W. (2009) Clinical Characteristics and Complications Associated with Mesiodentes. Journal of Oral and Maxillofacial Surgery, 67, 2639-2643. http://dx.doi.org/10.1016/j.joms.2009.07.041

[29] Demiriz, L., Mısır, A.F. and Durmuşlar, M.C. (2015) The Prevalence and the Characteristics of Supernumerary Teeth of Children and Young Adolescents from North-Western Region of Turkey. BJMMR, 7, 369-377.

[30] Anthonappa, R.P., King, N.M., Rabie, A.B. and Mallineni, S.K. (2012) Reliability of Panoramic Radiographs for Identifying Supernumerary Teeth in Children. International Journal of Paediatric Dentistry, 22, 37-43. http://dx.doi.org/10.1111/j.1365-263x.2011.01155.x 